AQ1

\title{
Deep Brain Stimulation Through the "Lens of Agency": Clarifying Threats to Personal Identity from Neurological Intervention
}

Eliza Goddard, 1 ,*

Phone +61362262258

Email Eliza.Goddard@utas.edu.au

AQ2

${ }^{1}$ School of Philosophy, ARC Centre of Excellence for Electromaterials Science AQ3

, University of Tasmania, Hobart, Australia

\section{Abstract}

This paper explores the impacts of neurological intervention on selfhood with reference to recipients' claims about changes to their self-understanding following Deep Brain Stimulation (DBS) for treatment of Parkinson's Disease. In the neuroethics literature, patients' claims such as: "I don't feel like myself anymore" and "I feel like a machine", are often understood as expressing threats to identity. In this paper I argue that framing debates in terms of a possible threat to identity - whether for or against the proposition, is mistaken and occludes what is ethically salient in changes from DBS. Rather, by adopting a relational narrative approach to identity and autonomy, I show that the ethically salient issue from DBS is impacts on autonomous agency whether one's actions and beliefs are one's own, and how DBS may hinder, or foster, embodied, relational autonomy competences. This approach recognizes that if sufficiently significant, impacts on autonomy competences may pose a threat to one's ability to contribute to the process of authoring one's own life and so pose a threat to identity formation. I argue this approach resolves the confusion in the literature about whether and how DBS threatens identity and provides a complex picture of how DBS may affect selfhood by disrupting narrative identity formation and revision, distorting agency and/or undermining autonomy. 


\section{Keywords}

Personal identity

Autonomy

Deep brain stimulation

Agency

Authenticity

\section{Introduction}

Personal identity is an important concept for neuroethics and questions about identity are raised by emerging technologies designed to treat motor and psychological disorders; for example, the use of Deep Brain Stimulation (DBS) to treat motor symptoms of Parkinson's Disease (PD) or to treat depression or Obsessive Compulsive Disorder. If a person's selfhood consists in being an integrated, autonomous, self-reflective agent, then psychological and cognitive changes, whether the result of illness, or neurological intervention, are normatively significant. This concern is particularly salient if we consider that in addition to treatments, emerging neurotechnologies may be used for the purposes of enhancement of neural capacities beyond the current maximum normal human range.

Despite successful treatment for motor disorders associated with PD, some DBS recipients report changes in their sense of self or self-understanding and some express concern about psychological and personality changes. For example, they make statements like: "I don't recognize myself anymore", "I haven't found myself after the DBS" and "I feel like a machine", as quoted in papers by Schüpbach and colleagues $[1,-$ p.1812]. Many writing in neuroethics draw on these reports in their interpretation of the impacts of DBS on selfhood and identity, however theorists are divided concerning the normative significance of these types of changes. Some question whether DBS may threaten personal identity [2] and/or agency [3]. Some dismiss claims that DBS threatens identity, arguing that the salient issue is impacts on autonomy [4, 5], still others that authenticity is a matter of concern $[6,7]$.

In this paper I argue that framing debates in terms of a possible threat to identity - whether for or against the proposition, is mistaken and occludes what is ethically salient in changes from DBS. Rather, by adopting a relational narrative approach to identity and autonomy, I show that the ethically salient issue about DBS is the impacts on autonomous agency - whether one's actions and beliefs are one's own, and how DBS may hinder, or foster, embodied, relational autonomy competences. This approach recognizes that if sufficiently significant, 
impacts on autonomy competences may pose a threat to one's ability to contribute to the process of authoring one's own life and so pose a threat to identity formation. I argue this approach resolves the confusion in the literature about whether and how DBS threatens identity and provides a complex picture of how DBS may affect selfhood by disrupting narrative identity formation and revision, distorting agency and/or undermining autonomy.

To make this argument, I draw on three recent interpretations of the reported impacts of DBS on selfhood by Marya Schechtman [8], Françoise Baylis [9], and Catriona Mackenzie and Mary Walker [10]. Each applies a narrative approach to identity in their evaluation of the reports of self-change following DBS presented by Schüpbach and colleagues, yet highlight different ethical foci - narrative flow, agency and autonomy competences respectively. By bringing these three approaches into further conversation with one another, I show how an embodied relational approach to identity and autonomy, as prosecuted by Baylis, and Mackenzie and Walker respectively, develops Schechtman's approach to narrative self-constitution, recognizing more fully the role of others in narrative uptake, as well as the distinction between narrative identity and autonomy. I argue, this shifts the focus of ethical inquiry from changes in personality and psychology to autonomous embodied relational agency. In so doing, I set out an understanding of selfhood that I think better accounts for the impacts of DBS on personal identity, and which clarifies the central concepts at issue and their interrelation.

In section "Deep Brain Stimulation and Threats to Personal Identity" section I demonstrate the diverse and sometimes conflicting claims made for the saliency of identity, agency, autonomy and authenticity in statements about self-change consequent on DBS in the neuroethics literature and show that the concepts need clarifying in order to adequately account for whether and how DBS might threaten personal identity. In section "Narrative Disruption Through the "Lens of Agency" "section I set out Schechtman's claim that DBS threatens identity by disrupting the narrative thread and Baylis' contrasting argument that the impacts of DBS are better understood through "the " lens of agency". In section "Narrative Agency and Autonomy Competences" section, to flesh out Baylis' claims about the lens of agency, I set out Mackenzie and Walker's account of the impacts of DBS on autonomy competences. I further draw on Mackenzie's argument that Schechtman's narrative approach conflates autonomy and identity, to show how a focus on psychological and personality change as the central focus of ethical inquiry obscures the proper focus on embodied autonomy competences. In the final section "Conclusion" section I provide a summary of the argument. 


\section{Deep Brain Stimulation and Threats to Personal Identity}

DBS is used to treat symptoms of neural disorders, including motor disorders associated with Parkinson's Disease (PD), a progressive, degenerative condition. DBS occurs through an implanted "brain-pacemaker" device, or neurostimulator, which delivers electrical stimulation to targeted areas of the brain, controlling motor symptoms associated with PD, including tremors and shakes. ${ }^{1}$ Evidence of the effectiveness of DBS is found in clinical studies reporting by manufacturers and the media. Patient testimonies to the efficacy of DBS in controlling motor disorders associated with PD and allowing patients with PD to reengage in daily activities are also prevalent on the internet. ${ }^{2}$

Whilst DBS has been shown to improve motor symptoms associated with PD, some clinical studies, such as those by Schüpbach and colleagues, describe what they call problems of psycho-social adjustment $[1,11]$. These studies draw attention to the experience of patients for whom the DBS may have treated the motor symptoms (at least until the disease progresses), yet patients reported changes in their self-understanding and their relations with others, at home and in their professional lives. Patients reported feelings of self-estrangement such as in claims like: "I feel like a machine ... I don't recognize myself anymore" [1, p. 1812]. This reference should read:

([1] p. 1812) Some reported feeling enlivened: "During all those years of illness I was asleep. Now I am stimulated, stimulated to lead a different life" [1, p.

1812]. This reference should read:

([1] p. 1812) Partners, and significant caregivers, also noted changes in recipients, with some expressing contradictory reports to their partners concerning these changes, their understanding of them and the respective impact on their lives. ${ }^{3}$

In evaluations of the moral psychological impacts of DBS for PD on personal identity, the patient reports from Schüpbach and colleagues' studies have been cited extensively, in fact they appear to have been responsible for generating much of the literature on DBS and identity. ${ }^{4}$ Despite their common use, evaluative accounts in the neuroethics literature are divided as to how to interpret the normative significance of these personal changes, with differing and sometimes conflicting conclusions drawn about the ethical significance of the changes. Some express the concern that DBS may threaten personal identity $[2,3,15]$. Glannon, for example, states that whilst DBS may improve physiological (and psychological) symptoms of some conditions 'it may alter a range of mental states critical to thought, personality and behavior. This can 
disrupt the integrity and continuity of the psychological properties that constitute the self and one's experience of persisting through time as the same person' ( [2,--p. 289$]$ This refernce should read:

([2] p. 289) . Lipsman and Glannon, in addition to concerns about threats to identity - what it means to persist as the same person, raise concerns about threats to agency - what it means to be the source of one's thoughts and actions [3].

Of those expressing concern that DBS threatens personal identity, many are concerned with changes to personality following from DBS treatment for PD. These include aggressiveness, hypomania, but also changes in commitments and beliefs. Witt et al. express the worry that changing a person's core psychological characteristics or commitments through direct intervention might change that person into a different person [16]. This type of concern echoes concerns raised in the literature on neuropharmaceuticals, for example that changes from Prozac might threaten a person's identity by threatening their authenticity $[17,18] .^{5}$ Even when the patient desires and/or endorses the changes, this new personality is not theirs, they are not being true to themselves.

In contrast to those who argue DBS threatens identity by changing core characteristics, many in the neuroethics literature argue that it is mistaken to view DBS as threatening identity and that this charge is based on a mistaken and static view of identity $[4,5,18,20]$. In these discussions narrative identity is contrasted with numerical identity or metaphysical identity. Numerical identity concerns the relation that each thing bears to itself and nothing else. The numerical identity of a person over time, as well as the unity of a person at a time, have been defined in terms of psychological and biological criteria. In contrast, narrative approaches are concerned with a conception of "who" one is, one's commitments, biography, roles and psychological characteristics. This shifts the focus to our practical or evaluative concerns with personal identity. Changes in numerical identity correspond to people going out of, or coming into, existence. As Schermer notes: 'A change in numerical identity would mean that someone literally became someone else'-[5, p. 2 ] This reference should read ([5] p. 2)

and so if such changes were caused by DBS, it would be ontologically problematic, but 'changes in narrative identity are not necessarily problematic in themselves', people change and personal identity is not static but develops over time.

Schechtman's approach to narrative self-constitution has been highly influential in the neuroethics literature on DBS. ${ }^{6}$ However, whilst most agree that narrative identity is at stake in changes from DBS, there is disagreement about whether 
changes to narrative might present a threat to personal identity. Some, including Schechtman, argue that the disruption caused to the narrative thread by DBS could amount to a threat to identity $[8,22]$, whilst others, as implied in the quote from Schermer above, argue that change is not a threat but consistent with identity formation. DeGrazia, in discussion about neurological intervention and enhancement, argues that a narrative approach precludes the conclusion that narrative change represents a threat to identity, or authenticity, rather the salient question is whether the person chooses their altered personality [23]. ${ }^{7}$

Following on from these claims, many argue that the salient concept in discussions about changes from DBS is not identity, but autonomy [4, 5, 20]. As Synofzik and Schlaepfer put it: '[T]he ethically decisive question is not whether DBS alters personality or not, but whether it does so in a "good or bad way" from the patient's very own perspective' ([4], p. 4), that is, a concern with how the person finds the changes. Autonomy qua self-governance is understood as involving competence conditions and authenticity conditions, concerning one's relationship to one's motivational structure. Kraemer is also concerned about patients' autonomy, yet argues that the salient ethical concept in assessing the impact of DBS is authenticity, because recipients of DBS might endorse or identify with changes following DBS [7]. This is not authenticity as described above as being true to one's inner self, rather Kraemar draws on an account of authenticity as identification or endorsement of values or characteristics. Such accounts however are criticized for their failure to attend to the historical nature of our beliefs and commitments and so the social shaping of our ideas, as well as their overt identification of authenticity with unity of the will, thereby assuming that psychological conflict or ambivalence is antithetical to autonomous agency [24]. On identification or endorsement accounts, it is not clear what autonomy consists in, nor the relation to identity formation. Relational autonomy theorists point out, however, that the everyday exercise of our identities in its practical instantiation is often fraught with conflict and changes from DBS should be considered apiece with these.

To summarize: there are some shared positions, including critiques of accounts which rely on a static understanding of identity and an understanding that questions about self-change involve narrative identity, and theorists draw on the same patient reports. Nonetheless the authors draw contrasting conclusions concerning what is normatively important about self-changes following DBS, whether DBS poses a threat and what's the ethically salient concept or issue at stake - identity, agency, autonomy, or authenticity. As Schermer notes, this disagreement is in part due to there being no broad agreement on how to understand the key concepts at issue, and so the ethical significance of changes 
consequent upon DBS [5, p. 2]... This reference should read:

([5] p. 2)

I also accept that narrative accounts are better able to explain the sense of identity and identity change expressed by some patients in response to change following DBS, yet think none of the accounts discussed above fully captures what is ethically at stake in these changes. Further, there is a tendency in the literature to treat the impacts of DBS disjunctively - for example, DBS affects identity or autonomy or authenticity. As I will argue many of these accounts of the impacts of DBS focus on the ethical significance of personality change and conflate identity and autonomy, and in so doing they obscure a proper ethical focus on embodied autonomous agency. In what follows, I develop an approach to narrative which draws on Schechtman's approach to self-constitution, yet does not follow her conclusion that DBS presents a threat to identity by disrupting the narrative thread. By developing a relational approach to narrative identity, I show that the impacts of DBS should be understood through the "lens of agency" as either hindering or facilitating autonomy competences, drawing on approaches by Baylis and Mackenzie and Walker respectively, which may in turn impact on one's ability to contribute to authoring one's life. As I will show, this approach offers a contrasting understanding of the key concepts at issue, which both sets out the different conceptual domain of each concept, as well as articulating the connection between them.

\section{Narrative Disruption Through the "Lens of Agency"}

In her analysis of the impacts of DBS, Schechtman draws on a narrative approach to identity to explore whether DBS has the potential to threaten or alter personal identity in an ethically objectionable way. Schechtman argues that statements made by Schüpbach's DBS recipients, such as "I don't recognize myself anymore", concern recipients' conceptions of "who" they are - that is, their self-conception, and can be made sense of by employing a narrative selfconstitution approach to questions of identity and change. A narrative approach reveals that DBS can threaten identity by disrupting the narrative flow and coherence of one's life and agency through challenging our understandings of ourselves as the cause, or in control, of our actions, motives and beliefs.

In her analysis, Schechtman dismisses what she terms "traditional" views of identity which conclude that DBS threatens identity based in understandings of a static conception, that is in terms of changes to core or key psychological traits that define the true self. On the "traditional" view, a threat to identity would involve the removal or diminishment of these traits, so that you would no longer be 'you'. In contrast, on the narrative approach, our identity is tied to our ability 
to understand ourselves and others in narrative terms. This narrative approach to self-constitution is dynamic and, as Schechtman writes, continuity of narrative is thoroughly compatible with change, even radical change.

On Schechtman's narrative self-constitution view, a person's identity - their sense of self and their commitments, beliefs and values - is constituted by a self-conception that is narrative in form: we describe and explain what happens to us by drawing on elements used when telling a story. This activity creates a coherent and continuing self [25]. We are selves and agents in so far as we experience and live our lives as narratives. Through the creation of a coherent and continuing self, we are able to exercise agency. On Schechtman's account, not just any narrative is identity-constituting - an identity-constituting narrative must be capable of articulation and must 'cohere with reality' (that is, with others' understandings of the basic observational facts about the world and the lives of persons) ([25], p. 83)]. So we constitute our identities by employing an autobiographical narrative which meets these constraints. If one's narrative does not meet these constraints their continuity of experience, their agency, is challenged. For Schechtman, if one's identity is diminished, so is one's capacity for agency.

In applying her narrative self-constitution view to the reports by DBS recipients, Schechtman argues the claims made by recipients can be understood as stemming from disruptions to their narrative thread. Schechtman writes: 'According to the narrative approach, a threat to selfhood or identity stems from a disruption of the narrative flow of life' ([8], p.137). The responses of self-alienation and perceived negative changes amongst Schüpbach's respondents, such as: "I haven't found myself after the DBS", reveal a loss of, or gap in, the organizsing principles which structured the patient's self-narrative - the patterns of meaning and projects that formed around these self-understandings, including for example, a person's understanding of herself as having an illness. As such, patients may become confused about how to proceed and may have difficulty seeing their lives following DBS as continuous with their lives before DBS, and so narrative disruption may challenge the overall coherence of a person's life as well as their sense of themselves as a continuous self or agent.

In addition to disruptions to the narrative flow, Schechtman argues that DBS can directly threaten agency $[8,22]$. Drawing on cases where a patient has undergone an abrupt or significant change in their behaviour and mood [8] or values [22], Schechtman claims it is difficult to see the agent as the cause, or in control, of their behaviour; rather the only plausible explanation is these changes are caused mechanically by the DBS, in a way somewhat akin to brainwashing. This further challenges identity and selfhood [8]. On Schechtman's account, the 
recipient of DBS who has undergone psychological change is unable to tell an identity-constituting narrative that includes the fact of DBS. If a person's values, motivations and actions are the result of DBS, this is at odds with the articulation constraint for identity-constituting narratives - they cannot explain how their actions flow from their own plans and motives, because these have been caused by the machine. Thus, they cannot meet the articulation constraint. Further, if that person was to insist that their plans and motives were their own and not caused by the DBS, they would then fall foul of the reality constraint, as their self-narrative would not cohere with basic observational facts about the world [22]. As such, through this threat to agency, the person's identity is diminished.

Nonetheless, Schechtman claims that narrative self-constitution, because it is dynamic, offers a direction for repair because it stresses the continuity of a life's narrative and articulates the role of the agent as the protagonist of this narrative. Whilst there's the potential for narrative disruption, this need not be realised as a threat to identity. In such cases the narrative approach encourages patients to see a break in their narrative as a small segment in a continuous and self-expressive, single ongoing story [8].

This direction for repair suggested by Schechtman however is precluded by Schechtman's claim that DBS threatens identity by disrupting the narrative flow and her assessment of the ethical significance of the impacts of DBS in terms of psychological change or alteration. Whilst I endorse the narrative approach, and draw heavily on Schechtman's self-constitution approach to narrative, I argue that in order to adequately account for the impacts of DBS and offer directions for repair, we must focus directly on agency and better distinguish between concepts of identity and autonomy. To make this argument, I draw on Baylis' dismissal of claims about threats to identity and her focus on the "lens of agency" (in the following paragraphs) and Mackenzie and Walker's focus on autonomy competences and the distinction between the conditions of selfhood and the skills used in governing that self (in the following section).

Baylis, whilst adopting Schechtman's view that responses to DBS raise questions about "who" one is, as well as being broadly sympathetic to Schechtman's narrative self-constitution view, and equally dismissive of threats based on static conceptions of identity, argues that Schechtman's claim that DBS threatens narrative identity is mistaken and at odds with her more fundamental claims about identity and change. Baylis adopts an embodied relational approach to identity to argue that changes from DBS are best understood through the "lens of agency". 
For Baylis, relational identity is 'a dynamic interpersonal activity based in narrative' which understands narrative self-constitution in terms of the projection and uptake of narratives, which when successful, allow an agent to achieve narrative equilibrium; that is, uptake by others of one's preferred self-narrative [26]. Whether an identity-constituting narrative can be enacted is a matter of achieving equilibrium between one's self-understanding and what others allow us to be within the constraints of embodiment. Baylis' account of identity constitution stresses $\mathrm{co}$-creation or $\mathrm{co}$-negotiation; our identities emerge in these negotiated spaces between oneself and others. Whilst Baylis recognizes that Schechtman's account is relational, she challenges Schechtman's view that identity-constituting narratives are in the main constituted by an individual's subjective self-understanding [26]. Specifically, Baylis' account of co-authoring draws attention to the need to negotiate first- and third-personal ascriptions - the equilibrium constraint recognizes that narratives are subject to uptake, and so contrary to Schechtman, successful identity-constitution is not just a matter of whether one's narrative coheres with reality and is capable of articulation. On Baylis' understanding, disruptions to the narrative thread should not be conceived as 'threats' to identity as there is no guaranteed or set narrative other than that for which one can get uptake. Rather, disruptions represent a shift in the parameters of the continual negotiation of identity. Schechtman's account relies upon an assumption that, but for the DBS, the patient's identity-constituting narrative would be quite different; that is, DBS acts as a narrative distortion or constraint. As Baylis puts it, Schechtman's account sees DBS as placing a constraint on how a person sees and understands herself which interferes with identity-formation. However, this seems to render all change problematic or disruptive - any and all change could turn out to be identity-threatening and as Baylis notes, this conclusion does not sit well with Schechtman's claim that her narrative approach is consistent with change. Rather, Baylis argues, what's important is how narrative change is integrated; a process that is itself relationally transacted.

In contrast, drawing on instances of compulsive gambling following treatment with DBS, Baylis argues that if there is a threat from DBS, it is not to identity, but is best viewed through the lens of agency. That is, the threat to one's selfdirected agency. In such circumstances, patients are not responsible for their actions, their actions do not flow from their intentions and beliefs, but rather the DBS. Baylis writes: 'A ... plausible response to the question "Is DBS for PD a threat to personal identity?" suggests that DBS is such a threat but only insofar as it is a threat to agency - the ability to make informed and rational choices-as when a person's actions do not flow from her intentions or beliefs but rather are the result of direct brain manipulation.' ([9], p. 524). On this account, the claims 
such as "I feel like an electric doll", and "I feel like a robot", reveal a sense of self-estrangement and self-alienation that results from this threat to agency. These threats to agency are related to identity - if the threat is significant, argues Baylis, the person may be unable to meaningfully co-author their lives and contribute to the process of their identity-formation and so may lose hold of a sense of themselves, and thereby a sense of self-continuity ([9], p. 525). For Baylis the impacts of DBS are better understood, not as presenting a direct threat to identity, but rather through the "lens of agency" as threats to capacities for agency, specifically self-directed agency, which may in turn impact on capacities for identity (co)negotiation.

On Baylis' account, people undergoing DBS may face a further threat to identity from social understandings of disability and illness that result in discrimination, stigmatization and alienation. As Baylis explains, these negative assumptions constrain or limit the types of identity-constituting narratives available to those with illness and impairments and an agent's ability to actively contribute to coauthoring their own lives; these negative assumptions may also become integrated into one's self-understanding. Baylis writes: 'The threat, such as it is, are the beliefs and attitudes of others that result in stigmatization and alienation, which in turn may result in negative experiences and feelings being integrated into one's identity-constituting narrative.' ([9], p. 523). So, for Baylis, it is not DBS (or PD) that threatens identity (though she recognizes that neurological intervention and illness can be disruptive of the process of identity formation, as noted in the previous paragraph), but rather discriminatory social attitudes that may limit uptake of positive narratives and become integrated into and distort one's identity-constituting narrative. This eaffects one's ability to meaningfully author one's life, to contribute to the process of identity formation, and so undermines autonomous agency.

So, on Baylis' account the sense of alienation expressed by recipients of DBS is better explained as a threat to agency, either as the effect of direct brain interventions and/or the result of the internalization of social stereotypes that impair a person's capacities for autonomous agency. The claims about selfalienation can be understood as expressing both concerns about impacts of DBS on agency, but also concerns about impacts of (the internaliszation of) stereotypes, that constrain identity formation. These are not centrally claims about a perceived threat to personal identity, but primarily expressions of selfalienation or self-estrangement, indicating a distortion of agency and the possible undermining of autonomy. Contra Schechtman whose concern is to assess the impacts of DBS via disruptions to the narrative thread, Baylis' concern is to articulate narrative change and disruptions to narrative formation through agency, and impacts on narrative constitution and authoring through these 
impacts on agency. Baylis' uses of the phrase the "lens of agency" draws attention to the embodied and relational setting in which both DBS and the role of others is understood. As such it provides a more nuanced context through which the impacts of DBS should be understood. One's embodied sense of self is experienced in and through relationships with others and so the impacts of DBS will be experienced in these ways. This focus on others' understanding of us and the internalisz ation of others' understandings of us recognizes that our stories are always co-creations, and our efforts at autonomous agency are in and through others. The relational approach understands changes from DBS as apiece with the influence of others and not as a prima facie threat to narrative identity.

Further, Baylis' exhortation to understand the impacts of DBS through the "lens of agency", and her concomitant claim that viewing DBS as a threat to identity is deeply problematic, suggests that framing the discussion of patients' claims in terms of whether DBS alters or threatens personal identity in an ethically objectionable way is misplaced. It obscures the focus on agency and the real threats to identity from stigmatization and negative stereotypes. Baylis' modification of Schechtman's narrative approach and her exhortation to focus on agency is useful because it shifts ethical attention from the significance of personality change to the embodied experience of the impacts of the treatment. Contra Schechtman, this approach connects claims about impacts on agency and identity. However, Baylis' account of the lens of agency does not focus on the skills used in governing the self, and this bridge is required to properly account for the impacts of DBS on selfhood.

To give further support to, and to flesh out, Baylis' claim that agency should be the focus of evaluating the impacts of DBS on selfhood, in the next section I draw on Mackenzie and Walker's application of a relational approach to autonomy (and identity) to patient reports of personal change consequent upon DBS and their claim that the salient ethical issue from these changes is the impact of the treatment on the exercise of autonomy competences. Further, I use their argument that "ethics of authenticity" accounts conflate identity and autonomy, and so obscure the proper focus on autonomous agency, to show how framing the debate in terms of the ethical significance of alterations to personality or psychological changes - that is, whether DBS poses (or does not pose) a threat to identity - is mistaken. In doing so, I distinguish between narrative identity and autonomy, thus further setting out the distinction and the interrelation between the key concepts at issue in selfhood and so for assessing the impacts of DBS.

\section{Narrative Agency and Autonomy Competences}


Mackenzie and Walker evaluate the same patient responses to DBS, cited in Schüpbach and colleagues and discussed throughout this paper, and like Schechtman, Baylis (and others), argue that the sense of identity at stake in these claims about personal changes following DBS is narrative identity. They draw on Baylis' narrative equilibrium account (as set out in the previous section) to explain patients' reports of self-estrangement, arguing that the descriptions of self-estrangement reveal an inability to achieve equilibrium in one's self narrative. They write: 'This distress [in achieving equilibrium], in our view, points to threats to autonomy, rather than to identity or authenticity, as the salient concern underlying narratives of self-alienation' ([10], p. 390). Drawing on a relational approach to autonomous agency which understands autonomy as the exercise of a suite of skills or competences, they argue that the ethical focus should be on whether DBS facilitates or hinders the exercise of autonomy competences.

This analysis draws on Meyers' formulation of relational autonomy as the exercise of a set of skills, or "autonomy competences", for self-realization, selfdetermination and self-evaluation [27]. These competences are developmentally acquired through relation with others and are intersubjectively exercised, and can be both facilitated and hindered through this process. On Meyers' account, authentic selfhood emerges through the exercise of these competences: it is neither discovered nor justified through a process of endorsement. In addition to this process, Mackenzie argues that relational autonomy must be understood in constitutive terms, and not solely in causal terms; that is, an approach which takes intersubjectivity and relationality as part of the defining conditions of autonomy, and not just a concern for the impacts of intersubjectivity on an agent's capacity to exercise autonomy competency. ${ }^{8}$ On Mackenzie and Walker's view an adequate approach to relational autonomy is one that, in addition to the exercise of autonomy competences, includes recognition of the need to value one's own judgment and capacity to act in accordance with what one values; that is, one must have a specific normative commitment to oneself. This draws attention to the role of "normative competences", such as self-referring attitudes like self-trust and self-respect, in facilitating, or undermining, autonomous agency. On Mackenzie and Walker's interpretation, autonomy and normative competences are narratively structured. So, changes in competence can affect narrative coherence and changes in narrative coherence can affect the exercise of competences: they are not the same but interrelated.

Mackenzie and Walker argue neurotechnologies may impair or foster autonomy competences, which in turn bears on the ability to engage in the skills of narrative understanding, including narrative self-revision, in both positive and 
negative ways. Like Baylis, they recognize that DBS can cause disruptions and these may be profound enough to alter identity by impairing capacities for agency. They write: 'In some cases ... an intervention such as DBS can disrupt a person's autonomy competences to such an extent that he is unable to engage in narrative self-revision. In other cases, neurological interventions, by alleviating the physical or psychological effects of illness ... may thereby restore some of the volitional, emotional, motivational, imaginative, and critically reflective capacities necessary for autonomous deliberation and action. In doing so, such interventions may make it possible for a person to reengage in the process of reconstructing or repairing an integrated narrative identity. Relational theory shows, however, that a person's ability to do so is not just up to the person him or herself; it is also a matter of the extent to which others enable him/her to do so, by providing the social scaffolding and recognition required for autonomous self-narration.' ([10], p. 390). Like Baylis, their relational account picks out how both the impacts of DBS and social relations can distort agency and undermine autonomy, which may in turn affect identity formation and revision. This focus on autonomy competences fleshes out Baylis' claim that the impacts of DBS should be understood through the "lens of agency", providing a conceptual clarification and articulation of the relation between identity constitution and autonomous agency. Further, in what follows, I argue that conflating, or failing to properly distinguish between, identity and autonomy, provides an explanation of how the focus on the impacts of autonomous agency has been obscured, in favor of a focus on the significance of personality alteration and potential threats to identity.

Mackenzie and Walker contrast their relational approach to identity and autonomy and evaluation of the impacts of DBS in terms of autonomy competences with "ethics of authenticity" accounts which they argue are inadequate and misleading for assessing the ethical significance of changes consequent upon DBS. Ethics of authenticity accounts include not only accounts that seem to understand authenticity in terms of one's true self, for example Elliot [17], but also accounts, like DeGrazia's which argue for authenticity in terms of self-creation [23]. Mackenzie and Walker argue both types of account, despite their differing conclusions about whether psychological change consequent upon DBS presents a threat to identity via authenticity, fail to adequately account for the impacts of DBS because they conflate identity and autonomy and in so doing obscure the real focus on autonomy. ${ }^{9}$ Self-creation accounts elide identity and autonomy by construing self-creation/selfconstitution as the exercise of one's authentic self. By arguing that both sides of the ethics of authenticity debate are conceptually mistaken, Mackenzie and Walker's critique draws attention to the way the debate has been illicitly framed in terms of threats to personal identity, via claims about authenticity. 
In contrast, Mackenzie and Walker's relational approach explicitly distinguishes between identity and autonomy, that is, between the conditions of selfhood and the skills used in governing that self. As such it conceptually opens up a space for thinking through the difference between these concepts and their interrelation, and so they can attend to the relationship between changes to the exercise of autonomy competence, the effect on narrative coherence and selfunderstanding and the importance of self-referring normative commitments to self-governance. Furthermore, this relational autonomy approach whilst critical of authenticity conditions that rely on unity of the will, leaves open a conceptual space for thinking about self-conflict as a part of, and not inimical to, identity. On this approach one might be capable of projecting an identity-constituting narrative, yet have diminished or compromised autonomy.

Schechtman's narrative self-constitution approach, like ethics of authenticity accounts, fails to adequately distinguish between identity and autonomy. I argue that it is this conflation between identity and autonomy in Schechtman's account that leads her 1) to frame the effects of DBS in terms of the significance of personal change and 2) to conclude that DBS threatens identity. I agree with Mackenzie and Poltera [29], who in a piece on the impacts of schizophrenia on identity and autonomy argue that Schechtman's account conflates identity and autonomy, because it does not sufficiently distinguish between agency over time (narrative self-constitution) and capacities for autonomy. This conflation is in part because the constraints Schechtman places on identity-constituting narratives are too strong, requiring a high degree of coherence, affective identification, and self-knowledge ([29] p. 45ff]. In so doing, whilst having a concern for the impacts of DBS on identity and agency, Schechtman is unable to properly articulate the difference between the impacts of DBS on narrative selfconstitution and the skills used in self-governance; on her account identity are and autonomy are too closely linked.

As I argued above, by drawing a clearer distinction between identity constitution and self-governance, the relational account can allow for the exercise of narrative constitution, whilst recognising diminished capacities for autonomy. In their account, Mackenzie and Poltera modify Schechtman's reality constraint through reference to a distinction between a narrative and its content. This 'looser conception of narrative self-constitution' allows for the incorporation of an 'illness' narrative into an agent's self-conception without endorsing the contents of that narrative. In doing so they can allow for identity-constitution via overlapping and conflicting fragments but still recognize diminished autonomy. With this modification, Mackenzie and Poltera offer us a way of making good on Schechtman's claims that narrative self-constitution offers directions for repair 
by allowing for the possibility of including a DBS narrative that is identity constituting whilst still recognizing the impacts of DBS on autonomous agency.

By drawing on Mackenzie and Walker's relational account of autonomy competences I have 'fleshed out' further, that is, provided further content for, Baylis' argument that the impacts of DBS should be understood through the "lens of agency". I have also further developed a relational narrative approach to identity and autonomy, which sets out the impacts of DBS in terms of how these concepts inform agency - this account recognizes that DBS might have an impact, positively or negatively, on the exercise of ones' autonomous agency which in turn may impact on the ability to engage in identity formation, and eenstitution and revision. The explicit focus on relationality as constitutive of identity shows how some accounts, including some narrative accounts, conflate autonomy and identity and so obscure the real focus on capacities for autonomous agency. This constitutively relational account both explains why the threat to identity talk gets going and is so persuasive, but also how framing impacts around threats to identity and authenticity is mistaken and obscures the focus on agency and the impacts of DBS on autonomy competences as the ethically salient focus. This analysis, I argue, clarifies, in part, the disagreements between Schechtman and Baylis, as well as Schechtman's argument that both identify and agency are important, as well as how changes to the exercise and experience of agency can in turn effect affect identity formation.

\section{Conclusion}

In this paper, I have argued that framing debates about the significance of DBS for identity in terms of the ethical significance of changes to personality or psychology is mistaken. To show this, I have set out a relational narrative approach to identity and autonomy, distinguishing between the central concepts involved in selfhood and their interrelation. By drawing on Schechtman, Baylis and Mackenzie and Walker, their agreements and disagreements, I have shown that the relational approach to identity and autonomy shifts the framing of the debate in terms of whether DBS alters identity or presents a threat to personal identity to one which focuses on the exercise of autonomy competences as seen through the "lens of agency". This approach shows that the salient issue is the impact of DBS on autonomy competences, which can be both facilitated and hindered. I have argued that the focus on autonomy competences gives us a standard by which to adjudicate the normative significance of changes consequent upon DBS. Further, I have demonstrated that threats to identity are still salient in two ways. Firstly, DBS, and illness, can pose threats to agency and to the exercise of autonomy competences, and these if serious/significant pose threats to identity such that one is unable to meaningfully author their lives and 
so lose a sense of themselves (even as selves). Secondly, negative understandings of disability can threaten identity by constraining the types of identityconstituting narratives available to those with impairments and illnesses and their ability to actively contribute to authoring their lives. This approach draws our attention to the vulnerability of those seeking treatments to the attitudes of others, attitudes which as relational autonomy theorists point out are structurally embedded in the social and institutional system.

By reflecting on the three interpretations of patients' experience of DBS by Schechtman, Baylis and Mackenzie and Walker and bringing them into further conversation with one another, I have developed a narrative account by drawing out the significance of relational identity and autonomy, the distinction, as well as the relation, between these concepts. On the relational approach I have provided no one concept is foundational, rather the accounts I have discussed set out the interrelation of these concepts. DBS can disrupt the narrative flow, distort agency and undermine autonomy. DBS might also facilitate autonomy and contribute to narrative constitution and revision. My approach to understanding the experience of DBS dispels the impression that the impacts of DBS on selfhood should be understood disjunctively, that is, to either identity or agency, or autonomy, or authenticity. That said, I do prioritize the way these are understood with the direction of explanation as follows: a focus on autonomy competencies helps to clarify claims about impacts of DBS on agency and thus potential threats to identity. This paints a complex picture of selfhood and is the type of approach to personal identity that I think is best able to understand the ethical issues arising from DBS.

Using the relational approach, I have showed that framing the debates about the impacts of DBS in terms of threats to identity rests on a conflation of identity and autonomy - this dispels the misconception, often presented in the neuroethics literature on the ethics of DBS, that the ethically salient question is the ethical significance of alterations to personality or psychology, and shows why autonomous agency has been obscured. This makes good on Schechtman's concerns about identity and agency and her claim that narrative can help patients pick up the pieces again, with recognition of the importance of others in this process, as well as the ongoing impacts of illness on one's selfhood.

\section{Acknowledgements}

Research for this project was supported by the Australian Research Council Centre of Excellence Scheme (Project Number CE 140100012).

\section{References}


1. Schüpbach, M., M. Gargiulo, and M.L. Welter. 2006. Neurosurgery in Parkinson's disease: a distressed mind in a repaired body? Neurology 66 : 1811-1816.

2. Glannon, Walter. 2009. Stimulating brains, altering minds. Journal of Medical Ethics 35: 289-292.

3. Lipsman, Nir, and Walter Glannon. 2013. Brain, mind and machine: what are the implications of deep brain stimulation for perceptions of personal identity, agency and free will? Bioethics 27(9): 465-470.

4. Synofzik, Matthis, and Thomas E. Schlaepfer. 2008. Ethical criteria for deep brain stimulation in psychiatric patients and for enhancement purposes. Biotechnology Journal 3: 1-10.

5. Schermer, Maartje. 2011. Ethical issues in deep brain stimulation. Frontiers in Integrative Neuroscience 5: 1-5.

6. Johansson, Veronica, Martin Garwicz, Martin Kanje, Jens Schouenborg, Anders Tingstrom, and Ulf Gorman. 2011. Authenticity, depression and deep brain stimulation. Frontiers in Integrative Neuroscience 5: 1-3.

7. Kraemer, Felicitas. 2013. Authenticity or autonomy? When deep brain stimulation causes a dilemma. Journal of Medical Ethics 39: 757-760.

8. Schechtman, Marya. 2010. Philosophical reflections on narrative and deep brain stimulation. The Journal of Clinical Ethics 21: 133-139.

9. Baylis, Françoise. 2013. 'I Am who I Am': on the perceived threats to personal identity from deep brain stimulation. Neuroethics 6(3): 513-526.

10. Mackenzie, Catriona, and Mary Jean Walker. 2014. Neurotechnologies, personal identity, and the ethics of authenticity. In Handbook of neuroethics, ed. Jens Clausen and Neil Levy, 374-392. Netherlands: Springer.

11. Agid, Y., M. Schüpbach, M. Gargiulo, L. Mallet, J.L. Houeto, C. Behar, D. Maltete, V. Mesnage, and M.L. Welter. 2006. Neurosurgery in Parkinson's disease: the doctor is happy, the patient less so? Journal of Neural Transmission Suppl 70: 409-414.

12. Blacher, Richard S., and Samuel H. Basch. 1970. Psychological aspects of pacemaker implantation. Archives of General Psychiatry 22: 319-323. 
13. Svenaeus, Fredrik. 2012. Organ transplantation and personal identity: how does loss of and change of organs affect the self? Journal of Medicine and Philosophy 37: 139-158.

14. de Haan, Sanneke, Erik Rietveld, Martin Stokhof, and Damiaan Denys. 2015. Effects of deep brain stimulation on the lived experience of obsessivecompulsive disorder patients: in-depth interviews with 18 patients. PloS One 10(8): e0135524. doi: 10.1371/journal.pone:0135524 .

15. Klaming, Laura, and Pim Haselager. 2013. Did my brain implant make me do it? Questions raised by DBS regarding psychological continuity, responsibility for action and mental competence. Neuroethics 6: 527-539.

16. Witt, Karsten, Jens Kuhn, Lars Timmermann, Mateusz Zurowski, and Christiane Woopen. 2013. Deep brain stimulation and the search for identity. Neuroethics 6(3): 499-511.

17. Elliot, Carl. 2003. Better than well: American medicine meets the America dream. New York: W. W. Norton \& Company.

18. Focquaert, F., and D. De Ridder. 2009. Direct intervention in the brain, ethical issues concerning personal identity. Journal of Ethics in Mental Health 4(2): 1-7.

19. Levy, Neil. 2007. Neuroethics. Cambridge: Cambridge University Press.

20. Schermer, Maartje. 2009. Changes in the self: the need for conceptual research next to empirical research. American Journal of Bioethics 9: 45-47.

21. Schechtman, Marya. 2011. The narrative self. In The Oxford handbook of the self, ed. Shaun Gallagher. Oxford: Oxford University Press.

22. Schechtman, Marya. 2009. Getting our stories straight: self-narrative and personal identity. In Personal identity and fractured selves: perspectives from philosophy, ethics and neuroscience, ed. D.J.H. Mathews, H. Bok, and P.V. Rabins, 65-92. Maryland: John Hopkins University Press.

23. DeGrazia, David. 2005. Enhancement technologies and human identity. Journal of Medicine and Philosophy 30: 261-283.

24. Mackenzie, Catriona. 2014. Three dimensions of autonomy: a relational analysis. In Autonomy, oppression and gender, ed. Andrea Veltman and Mark 
Piper, 15-41. Oxford: Oxford University Press.

25. Schechtman, Marya. 1996. The constitution of selves. Ithaca: Cornell University Press.

26. Baylis, Françoise. 2012. The self in situ: a relational account of personal identity. In Being relational: reflections on relational theory and health law, ed. J. Downie and J.J. Llewellyn, 109-131. Vancouver: UBC Press.

27. Meyers, Diana Tietjens. 1989. Self, society and personal choice. New York: Columbia University.

28. Mackenzie, Catriona, and Natalie Stoljar, eds. 2000. Relational autonomy: feminist perspectives on autonomy, agency, and the social self. New York: Oxford University Press.

29. Mackenzie, Catriona, and Jacqui Poltera. 2010. Narrative integration, fragmented selves, and autonomy. Hypatia 25: 31-54.

${ }^{1}$ DBS is also used to treat psychiatric disorders associated with Treatment Resistant Depression (TRD) and Obsessive Compulsive Disorder (OCD) and treatment sites in the brain depend on the condition. I confine my analysis to DBS for the treatment of PD.

${ }^{2}$ For example, in personal videos, such as by Mike Robbins ( https://www.youtube.com/watch? $\mathrm{v}=\mathrm{h} 8 \mathrm{tW} 1 \mathrm{Yv} 1 \mathrm{Ykc}$ ), as well as in personal testimonies such as on the Medtronics site ( https://www.medtronicdbs.com/parkinsons/personal-stories/index.htm ).

${ }^{3}$ Similar claims concerning changes in self-understanding have been made by recipients of pacemakers [12], and by recipients of organ transplants [13]. I do not claim that there is something unique about changes in self-understanding consequent on DBS. However, because DBS directly affects the brain, concerns about changes to identity and self-governance take on a special significance.

${ }^{4}$ Whilst there are other studies of patient's first-person phenomenological reports of DBS implantation for PD, as well as other conditions [14], the reports in Schüpbach and colleagues have been the most frequently cited examples. While I do not argue it here, it would be helpful if theorists were to draw on a wider range of case studies involving changes in self-understanding following DBS from which to draw generalizable claims about the impacts of DBS. By drawing on the patient reports I do not argue that all patient experience is the same or even that cohorts of patients have similar responses to DBS. Rather, I argue these first-person phenomenological accounts provided by Schüpbach and colleagues can inform our understanding of selfhood and personal identity.

${ }^{5}$ Levy [19] discusses and dismisses a similar concern, that neurotechnologies threaten identity because they directly manipulate the brain. 
${ }^{6}$ For an outline of varying formulations of narrative approaches to identity constitution, see [21 ].

7 DeGrazia argues that when there is concern about a threat to identity this is because there is static view of identity being mobiliszed (or a conflation of numerical and narrative different senses of identity).

${ }^{8}$ Mackenzie and Walker set out a weakly substantial approach to relational autonomy. There are numerous approaches under the relational autonomy banner, which I cannot discuss in this paper. For further discussion, see [28].

${ }^{9}$ Baylis also critiques an individualist strand in DeGrazia's narrative approach and argues his narrative approach is unable to sufficiently account for the conflict between first- and thirdpersonal ascriptions, see [26]. 